
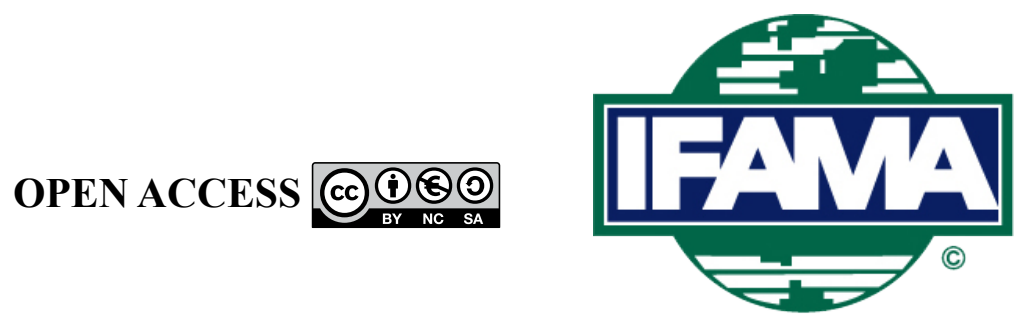

International Food and Agribusiness Management Review

Volume 25, Issue 2, 2022; DOI: 10.22434/IFAMR2021.0071

Received: 31 May 2021 / Accepted: 26 August 2021

\title{
Just a little bit more legumes! Results of an online survey in Europe \\ RESEARCH ARTICLE
}

\author{
Stéphan Marette ${ }^{\oplus a}$ and Jutta Roosen ${ }^{b}$ \\ ${ }^{a}$ Research fellow, Université Paris-Saclay, INRAE AgroParisTech, UMR Economie Publique, \\ Avenue Lucien Brétignière, 78850 Thiverval-Grignon, France \\ ${ }^{b}$ Professor, Technical University of Munich, TUM School of Management, \\ Chair of Marketing and Consumer Research, 85354 Munich, Germany
}

\begin{abstract}
A web survey was conducted in France, Germany, Poland, and the UK to examine how providing information about the benefits of legumes could influence purchase intent. In each country, 600 participants were recruited in September 2020. First, participants answered a series of questions about their dietary habits. Second, they were asked about their intention to purchase lentils, before and after they read an informational message about the nutritional or environmental benefits of lentils. The results show that receiving this information significantly affected purchase intent, even if the impact was relatively small. Indeed, after this revelation of information, about $10 \%$ of participants expressed a change of mind regarding their purchase intent. This effect was dependent on product type (i.e. dried lentils vs lentil pasta) and information type (i.e. nutritional vs environmental benefits). Across countries and products, information about the food's environmental benefits had often a greater impact on purchase intent than did information about the food's nutritional benefits. After reading the informational messages, $25-42 \%$ of all the participants said they planned to eat more legumes in the future. As consumers choices are weak drivers for developing legumes cultivation, other instruments focusing on farmers incentives such as subsidies could be selected.
\end{abstract}

Keywords: consumer behavior, legumes, nutrition, environment, web survey JEL code: C91, D12, Q18, Q16

\footnotetext{
${ }^{\circledR}$ Corresponding author: marette@agroparistech.fr
} 


\section{Introduction}

\subsection{General background}

In many developed countries, there is debate around the best way to improve dietary habits and nutritional practices (Tobler et al., 2011). Discussion most often centers on the types of foods that should be favored and the regulatory instruments that could help modify consumers' behaviors. Dietary habits also have direct consequences on both agricultural systems and natural resources (Lock et al., 2010), which means that numerous factors related to human and environmental health must be taken into account when recommending dietary changes. Indeed, it is important to reflect on all the complex relationships along the food production chain (Poore and Nemecek, 2018).

Among the various strategies for improving dietary habits, food substitution is an approach frequently recommended by scientists. However, to successfully introduce food substitutes, it is important to understand quantity-price relationships and/or to convince consumers to adopt new habits, which requires persuasion and information campaigns (Irz et al., 2015). In 2019, the EAT-Lancet Commission (Willet et al., 2019) proposed a 'universal healthy reference diet to provide a basis for estimating the health and environmental effects of adopting an alternative diet to standard current diets'. Drawing on extensive scientific research, the EAT-Lancet Commission has recommended certain drastic shifts that would generate a reference diet that meets current criteria for human health and environmental sustainability. For example, this new diet contains markedly higher levels of fruits, whole grains, legumes, vegetables, and nuts as well as significantly lower levels of red meat, tubers and starchy vegetables (Willet et al., 2019). In Europe, to achieve this diet, legume consumption would essentially have to quintuple, which would represent a major shift in the eating habits of European consumers.

Numerous studies have highlighted the positive effects of plant-based diets, which are heavily based on legumes, fruits, and vegetables, noting that such diets have benefits for both the environment and human health (Aiking and De Boer, 2020; Auestad and Fulgoni, 2015; IPCC, 2019; Lock et al., 2010; Tilman and Clark., 2014). Within this body of work, legumes (whose edible seeds are known as pulses) stand out as useful substitutes, serving as a good source of proteins, fibers, vitamins and minerals within a healthy and sustainable diet (Aiking and De Boer, 2020; González et al., 2011).

Additionally, the production of pulses such as lentils, peas, and beans offers important environmental benefits compared to the productions of other protein sources. For pulses (or legumes), González et al. (2011) clearly exhibit a high protein content and a high protein delivery efficiency in terms of energy use or greenhouse gas (GHG) emissions, compared to meat, dairy and eggs, cereals, fruits and vegetables (González et al., 2011: 566). Additionally, pesticide use is relatively low, and legumes can fix atmospheric nitrogen, eliminating the need for nitrogen fertilizer. When incorporated into crop rotations, legumes significantly boost the yields of subsequent grain crops (by up to 20\%; Knight, 2012). Given the widespread use of monocultures, legumes could help drive crop diversification, protect biodiversity and promote more sustainable agricultural practices (DiverImpacts, 2020). The European agriculture does not meet the 2030 Sustainable Development Goals, with major environmental problems/challenges regarding ammonia emissions, gross nitrogen balance, soil health, and farmland biodiversity (Matthews, 2020). A development of legumes/pulses cultivation would contribute to reach ambitious environmental goals along with nutritional benefits related to plant-based proteins.

Despite these numerous benefits, legumes consumptions do not reach recommended levels advised by many nutritional and environmental guidelines issued around the world, including the one from the EAT-Lancet Commission (Figueira et al., 2019; Mitchell et al., 2009; Willet et al., 2019). In such a context, a bold shift in consumer habits appears as a crucial but thorny challenge. Even if innovation such as meat alternatives (sometimes highly-processed) may play a role, this challenge mainly consists in boosting the consumption of classical products, such as legumes, fruits and vegetables, and invigorating traditional cooking practices. 
However, a regular consumption of legumes is constrained by many barriers, such as the weak knowledge in nutrition regarding plant-based possibilities (Aiking and De Boer, 2020), the inexistent purchasing routines of plant-based alternatives to animal proteins (Schösler et al., 2012), and/or the lack of cooking familiarity with legumes (Melendrez-Ruiz et al., 2020). Moreover, the numerous technical lock-ins at the farm level and the absence of economic incentives in the supply chain limit the supply of plant-based proteins, which simply reinforces the low consumption of plant-based proteins in diets (Magrini et al., 2016; Morel et al., 2020). All these reasons explain the focus of this paper on the consumption of one specific legume, namely lentils offered in a traditional way (dried) and in an innovative way (pasta). In this context, insistence on information about impacts on both nutrition and environment seems to be one of the main driving forces for convincing consumers of dietary shifts.

\subsection{Objective of the paper}

This study aimed to assess how sharing information with consumers could influence intended legume consumption. A web survey was conducted in four European countries to examine how providing information about the benefits of legumes could influence consumer purchase intent. In each country, 600 participants were recruited in September 2020, leading to a total of 2,400 participants. We chose to employ a web survey in this study because it is difficult to reveal scientific information to consumers under real-life conditions, such as in a supermarket. A within-subjects split study design was used: purchase intent was evaluated before and after each participant read a single informational message, which focused either on nutritional benefits or environmental benefits, including crop diversification, helping limit the use of chemical pesticides and synthetic fertilizers (Lin, 2011). Regarding purchase intents, new foods, such as lentil pasta were shown to some participants, while others indicated their purchase intent for the traditional product, such as dried lentils. Hence the study addresses the following research questions (RQ) a, b and c:

RQ a: Does information about legumes lead to higher purchase intent for legume products?

RQ b: Does the effect of information depend on the type of product, that is pure legumes or a processed product based on legume flour?

RQ c: Does purchase intent react more to information on environmental or nutritional benefit?

\subsection{Comparison with previous contributions}

Previous studies in this field have often addressed the question of how to best replace meat with plant-based substitutes made from grains and/or legumes (e.g. soybeans, peas, and/or lentils) (Lemken et al., 2019; Martin et al., 2021; Saint-Eve et al., 2021; Vainio et al., 2018; Weinrich, 2019; Weinrich and Elshiewy, 2019; Westhoek et al., 2014). Here, we chose instead to look at a single food type, lentils, in an attempt to shift the focus away from identifying meat substitutes and toward encouraging the consumption of a food with specific nutritional and environmental benefits. Also, instead of looking at plant-based alternatives to meat-based burger patties (Castellari et al., 2019; Slade, 2018), we looked at a legume-based pasta that can be characterized as a nascent innovation appearing on shelves at the time of this web-survey. The next section underlines a small market share of lentil pasta among all pasta products newly introduced on the markets in the countries covered by this study, which means a product that could appear as a possible option for developing new markets and new cooking practices. More specifically, we asked participants to express their intent to purchase either dried lentils or lentil pasta.

This study provides insights into how consumers/everyday citizens view crop diversification. Meier and Oehen (2019) study consumer acceptance for vegetable varieties and willingness to pay to preserve food diversity. Alcon et al. (2020) examined consumer willingness to increase monthly food expenditures to ensure that products originated from agricultural systems promoting crop diversification, protecting biodiversity, and fostering environmental services. Our work differs from these two studies because it focused on choices 
related to a single food, and it examined the influence of messaging centered on the food's nutritional and environmental benefits.

This manuscript is organized as follows: the methods are described in Section 2 and the results are presented in Section 3. A discussion is presented in Section 4 and the conclusions are laid out in Section 5.

\section{Materials and methods}

This section successively details the sample selection, the products, and the revealed information and the methodology. An overview of questions asked in the web-survey is presented in Appendix A and the complete questionnaire for the UK is presented in the Appendix (available on request; included for review as Appendix C). The web-survey was calibrated for lasting 15 minutes, in average, and for limiting the attention declines by participants.

\subsection{The sample recruitment}

The web-survey was conducted by a private company, Ifop, in four European countries, namely France, Germany, Poland and United Kingdom in September 2020. ${ }^{1}$ In each country, the sample consisted of 600 consumers aged between 18 and 70 years and was selected for being representative of the national population based on quotas for sex, age and income. For quotas by income, the income distribution was divided into three categories covering the lower four deciles and the upper four deciles as well as the central two deciles (5-6) of the income distribution in each country. In each of these 3 income categories we recruited 100 men and 100 women for a total of 600 respondents per country.

\subsection{The purchase intents for two types of lentils}

At the middle of the web-survey (Appendixes A of the Supplementary Material, and C upon request), purchase intents were elicited using a single bound dichotomous choice question. Related questions focused on lentils, because lentils are the legumes (or pulses) known and consumed across the four countries, but with a possible room of improvement in consumption levels as it will be shown in Table 2. Moreover, lentils are subject to new product developments by creating alternative products such as the pasta made with lentil flour. Table 1 shows the shares of pasta made with lentil flour among newly introduced pasta products over the years preceding the web-survey. While the shares are small, they show promising opportunities for this interesting new cooking option that could be promoted in the future. Cerri et al. (2019) underline the social desirability of such new sustainable products.

The main objective of this study is to measure the purchase intent for lentils and how it relates to product type and information on environmental and nutritional benefits. To this end, participants were partitioned into two equally sized subgroups, one subgroup to whom a $500 \mathrm{~g}$ package of dried lentils was offered, and an another

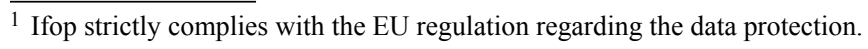

Table 1. Newly introduced pasta products (count) in the years 2016 to 2020 (Mintel, 2021).

\begin{tabular}{llllll}
\hline Country & $\begin{array}{l}\text { Without pulses as } \\
\text { ingredient }\end{array}$ & $\begin{array}{l}\text { With pulses as } \\
\text { ingredient }\end{array}$ & $\begin{array}{l}\text { With lentils as } \\
\text { ingredient }\end{array}$ & $\begin{array}{l}\text { Total number of } \\
\text { new pasta }\end{array}$ & \% of lentils \\
\hline Germany & 1,487 & 129 & 41 & 1,616 & $3 \%$ \\
France & 1,724 & 75 & 25 & 1,799 & $1 \%$ \\
UK & 855 & 65 & 26 & 920 & $3 \%$ \\
Poland & 687 & 40 & 12 & 727 & $2 \%$ \\
\hline
\end{tabular}


one to whom a $500 \mathrm{~g}$ package of pasta was offered. A picture of the products was shown in the web-survey, before asking their purchase intents (the second part of Appendix B). We presented the same simplified packets across the four countries, without providing any specific details on brands or any labeling as we could do for the organic label, for avoiding the idiosyncratic characteristics related to national information.

During two rounds \#1 and \#2, participants had to answer if at a given price $P$ they would purchase the product. For dried lentils or pasta made with lentil flour, they had to reply either 'yes', 'no', or 'maybe' (Appendix B of the Supplementary Material). This simple choice mechanism corresponds to a referendum style question, which is particularly tailored for measuring the impact of revealed information with heterogenous consumers. Regarding the option 'maybe', Loomis and Ekstrand (1998) underline some improvements coming from the incorporation of a degree of uncertainty related to the 'yes' answering option into estimation of the logit model. This referendum type question allows to get purchase intents for a generic product at realistic and credible market prices. This mechanism differs from a mechanism with differentiated products (and various characteristics) as estimated with a choice experiment and from a mechanism without reference to market prices as a 5 or 7-point Likert scale. Compared to these alternative mechanisms, the impact of additional information on a generic product like lentils is clearly evaluated with this referendum type mechanism.

For each participant, the randomly assigned price $P$ was the same for rounds $\# 1$ and $\# 2$, but this price was varying among participants as indicated in Supplementary Table S1. In order to account for price diversity, the values of the possible prices $P=\left\{P_{1}, P_{2}, P_{3}\right\}$ were close to values observed in supermarkets at the time of the online survey. These prices are presented in Supplementary Table S1.

We elicited hypothetical choices and no real product was given or sold at the end of the web-survey. Despite the risk of hypothetical and upward biases of choices, the web-survey is a tool for studying consumers' intentions with a satisfying control of the revealed information. For mitigating this risk of hypothetical bias, we provided a few lines of initial explanations for explaining the possible differences between their choices in the survey and the real choices. This cheap talk script is presented at the beginning of Appendix B of the Supplementary Material and was directly inspired by the one used in Lusk (2003).

The within subject-design of the online experiments allows us to assess the impact of new information on the environment or health for creating a demand for lentils or lentil pasta.

\subsection{The additional explanations before the purchase intents elicited at round \#2}

To measure the effect of information, a within-subject design was used. Between rounds \#1 and \#2, a dedicated screen was shown with either a message about the environment or a message on health. This screen was blocked during 10 seconds before it was possible to go to the next page for indicating purchase intents. Based on agronomic and nutritional publications, we favored relatively short messages, since Keller and Staelin (1989) showed that, if consumers receive too much information, then the marginal effect of any additional message tends towards zero.

For the subgroup of 300 participants, the message on the environment was the following:

Please read the following information:

Cultivating pulses such as lentils has environmental benefits.

No additional nitrogen fertilizer is required for the lentil crop because the leaves and roots of the plants naturally capture nitrogen from the air. As this nitrogen from the air is transformed into natural fertilizer in the soil, lentils are an excellent choice for the subsequent crops that are cultivated on the same area afterwards. Lentil cultivation allows:

- a yield gain of $10 \%$ for the next crop (wheat / corn); 
- saving 30 to $50 \%$ of nitrogen fertilizers for the next crop (wheat / corn);

- an improvement of the soil structure.

However, lentils are not widely grown in UK due to a lack of market opportunities, and/or a lack of organization in the supply chains. Eating lentil-based food products would increase their share in the cultivated crops in UK.

Now, we will ask you once more for your purchase intention for the same product. Feel free to change or keep your choice compared to what you indicated before.

For the subgroup of 300 participants, the message on health was the following:

Please read the following information:

Lentils are pulses that have many nutritional benefits.

Lentils do not contain cholesterol, and they are low in fat and sodium.

They are naturally rich in fibre, iron, folate and potassium, which are important nutrients for the body.

Finally, lentils are a very good source of proteins. By being part of a balanced diet, the consumption of vegetable proteins, especially lentils, is advised by nutritionists.

Now, we will ask you once more for your purchase intention for the same product. Feel free to change or keep your choice compared to what you indicated before.

For summarizing the design of the experiment in each country, Table 2 shows that the type of products (Research question, RQ b) and the messages (RQ c) were controlled by equally varying the type of products and messages across four randomly selected subgroups of participants creating all possible combinations of product and message. To each survey participant in any of these four groups of 150 participants each, a single price of Supplementary Table S1 was randomly assigned, so that, in total, we have 50 observations per product-message-price combination per country.

The 'symmetric' design of Table 2 allows to test three important parameters impacting the purchase intents, namely the type of products (dried or pasta), the message (health or environment), and the price with 3 different values of price $P=\left\{P_{1}, P_{2}, P_{3}\right\}$ equally divided inside each groups of 150 participants. These 3 parameters reflect a diversity of situations characterizing markets and the design of Table 2 allows to reply to RQ a, b and c (see Section 1.2).

Table 2. Number of participants in the different groups for each country with 600 participants. ${ }^{1}$

\begin{tabular}{lll}
\hline Message before round $\# \mathbf{2}$ & Products & Pasta \\
\cline { 2 - 3 } & Dried lentils & 150 participants: \\
\hline Health & 150 participants: & $P_{1}$ for $50, P_{2}$ for $50, P_{3}$ for 50 \\
& $P_{1}$ for $50, P_{2}$ for $50, P_{3}$ for 50 & 150 participants: \\
Environment & 150 participants: & $P_{1}$ for $50, P_{2}$ for $50, P_{3}$ for 50 \\
& $P_{1}$ for $50, P_{2}$ for $50, P_{3}$ for 50 & \\
& ${ }^{1}$ The specific values of the possible price $P=\left\{P_{1}, P_{2}, P_{3}\right\}$ are given in Supplementary Table $\mathrm{S} 1$.
\end{tabular}




\subsection{Data analysis}

To answer the RQ a to c, data analyses were performed using R software (R Foundation, Vienna, Austria). First, we looked at the descriptive statistics to describe sample characteristics regarding socio-demographics and consumption habits. Second, we focused part of our analysis on purchase intents for lentils. We tested whether the purchase intent between after receiving informative messages are different from the baseline purchase intent using the Wilcoxon test for paired samples.

We also used econometric estimators to analyze purchase intents country by country. We examined the impact of the informational messages by pooling the participants' choices for lentils during the two stages, leading to 1,200 observations for each country (namely, $2 \times 600$ participants). Given that each participant indicated purchasing intent twice, errors related to these variables were potentially correlated for each participant. Therefore, this random effect imposed constraints on the structure of the variance-covariance matrix. Moreover, the choices 'Yes' or alternatively 'No' and 'Maybe' gathered together as a single possibility correspond to qualitative variables and are estimated with a logit model. We therefore considered the logit estimator with random effects, which describes the relationship between the dependent variable and the independent variables. We used the R package $\mathrm{pglm}$ that approximates the likelihood function via a GaussHermite quadrature (Croissant, 2017; Lee, 2019).

Model 1 only retained variables strictly linked to the indications of purchase intents, namely the price, the type of product and whether purchase intent was measured before or after the revelation of information (RQ a). In this first model, we took into account the price $P$, and dummy variables (DV) for the type of product (RQ b) and for the informational text type (RQ c). The DV 'Pasta' was equal to 1 for the participants who saw the pasta and equal to 0 for the participants evaluating dried lentils (Appendix B of the Supplementary Material). The DV 'Info health' was equal to 1 when participants had been exposed to this text type and 0 otherwise, while the variable 'Info environment' was equal to 1 when participants were exposed to this text type and 0 otherwise. As consequence, both variables are zero in round $\# 1$ of the experiment. A second model considers the previous variables and explores the possible sway of participants' perceptions and socioeconomic characteristics. We tested the impact of these variables, and we only report regressions with the perception and socio-demographic variables having a significant impact for avoiding cluttering. When these variables do not significantly impact choice, we re-run final regressions without these variables. We report the final results under the heading number 2 .

\section{Results}

This section starts by presenting some descriptive statistics coming from questions asked at the beginning of the questionnaire. First, Table 3 presents some information about consumption habits regarding vegetables and legumes. Then it shows that the consumers in the surveyed countries know and eat pulses. However, consumption habits of lentils are limited and with a vast group of consumers eating pulses less than twice a week (the complement of figures of the penultimate line of Table 3). While in France, more than 53\% of consumers eat pulses twice a week or more often, the share drops to $22 \%$ in Germany. There is possibly room for improvement regarding the frequency of lentil consumption. The last line shows that organic consumption exists in all countries, but it is quite limited, less than one third in all countries, suggesting a sensitivity to environmental questions by a minority of consumers.

We now turn to the purchase intent for lentils, which was a central part of our questionnaire. Table 4 presents the average purchase intents for the two products and for the different countries. The signs $\Delta$ indicate the significant differences for a given product and a specific country between choices before (round \#1) and after (round \#2) the revelation of information. 
Table 3. Consumption habits.

\begin{tabular}{lcccc}
\hline & France & Germany & Poland & UK \\
\hline \% of participants consuming at least four times over the last year: & & & & \\
Salad & 85.8 & 73.7 & 76.3 & 73.7 \\
Carrots & 87.8 & 81.0 & 88.8 & 90.5 \\
Green Peas & 73.8 & 57.5 & 65.7 & 76 \\
Lentils & 72.3 & 41.8 & 33.8 & 33.8 \\
Beans & 83.0 & 61.8 & 73.8 & 76.8 \\
Chick peas & 37.5 & 19.7 & 26 & 31.7 \\
\% of participants knowing the meaning of the term 'pulses'? & 61.5 & 72.1 & 83.6 & 67.6 \\
\% of participants eating pulses twice a week or more (after a few & 53.3 & 22.0 & 37.8 & 49.8 \\
explanations about the pulses) & & & & \\
\% of participants eating exclusively or mainly organic fruits and vegetables & 20.1 & 23.6 & 30.3 & 13.1 \\
\hline
\end{tabular}

Table 4. Purchase intents before and after message by product and country. ${ }^{\text {a }}$

\begin{tabular}{|c|c|c|c|c|c|c|}
\hline & \multicolumn{3}{|c|}{ Dried lentils } & \multicolumn{3}{|l|}{ Pasta } \\
\hline & $\begin{array}{l}\text { \% of yes } \\
\text { round } \# 1\end{array}$ & Test $^{\mathrm{b}}$ for $\neq$ & $\begin{array}{l}\% \text { of yes } \\
\text { round } \# 2\end{array}$ & $\begin{array}{l}\text { \% of yes } \\
\text { round\#1 } 1\end{array}$ & Test $^{\mathbf{b}}$ for $\neq$ & $\begin{array}{l}\% \text { of yes } \\
\text { round } \# 2\end{array}$ \\
\hline France & 39.0 & $\Delta * * * \mathrm{c}$ & 45.6 & 26.6 & $\Delta * * *$ & 31.3 \\
\hline Germany & 24.3 & $\Delta * * *$ & 30.3 & 17.6 & $\Delta^{* * *}$ & 26.6 \\
\hline Poland & 37.0 & $\Delta^{* * *}$ & 45.6 & 23.3 & $\Delta * * *$ & 35.6 \\
\hline UK & 20.3 & $\Delta * * *$ & 23.3 & 17.0 & $\Delta^{* * *}$ & 22.0 \\
\hline
\end{tabular}

${ }^{a}$ This table reports the share of 'yes' responses to the question for purchase intent across all price levels and messages.

$\mathrm{b}$ The Wilcoxon test compares paired samples of choices between two successive rounds of information.

c The sign $\Delta^{* * *}$ denotes significant differences at $1 \%$ between choice successive rounds \#1 and \#2.

In Table 4, the percentage of 'Yes' for purchasing dried lentils at round \#1 is higher than the percentage of 'Yes' for purchasing pasta at round \#1 in all countries. Pasta based on lentil flour is a relatively new product offered in supermarkets, as shown in Table 1 in which shares of lentil pasta among new introduced products were small $(\leq 3 \%)$. The definition whether pasta made with lentils flours are totally new or just a kind of reformulation is debatable, but the novelty for consumers gives an interesting explanation about the low percentage of 'Yes' at round\#1. During the first round, the percentages of 'Yes' for the dried lentils or the pasta in different countries are relatively weak, namely very often lower than one third. Table 4 also shows that the purchase intents are significantly influenced by the reading of the messages. In average, Table 4 shows an increase in purchase intents in every country. There is a significant influence of additional explanations on consumers purchase intent, even if this impact is relatively weak with a changing proportion of consumers intending to consume the lentil products lower than $10 \%$. Note that even after the revelation of information, no country reaches a majority of 'Yes', suggesting some limits in the possibility of changing consumption. For UK, the pattern of purchase intents seems even a little bit different, possibly because they rather eat beans than lentils.

The econometric estimations of purchase intents for each country with 600 participants are presented in Tables 5, 6, 7 and 8 for measuring the impact of messages (results are robust with alternative regressions with pooled data gathering the four countries). Dummy variables (DV) are indicated by the following notation $(1 / 0)$, meaning that the variable is equal to 1 for the corresponding characteristic and 0 otherwise (see Section 2.4 for a precise description of DV belonging to Model 1 and also used in Model 2). 
Table 5. Estimations of purchase intents in France with random effects logit estimator. ${ }^{\mathrm{a}}$

\begin{tabular}{|c|c|c|}
\hline Independent variables & Yes Model 1 & Yes Model 2 \\
\hline Price & $-0.945 * * *(0.162)$ & $-2.011 * * *(0.428)$ \\
\hline Pasta $(1 / 0)$ & $-1.170 * *(0.531)$ & $-2.709 * * *(0.546)$ \\
\hline Info health $(1 / 0) \times$ Pasta $(1 / 0)$ & $1.168 * *(0.523)$ & $1.111^{* *}(0.522)$ \\
\hline Info environment $(1 / 0) \times$ Pasta $(1 / 0)$ & $1.181 * *(0.521)$ & $1.127 * *(0.541)$ \\
\hline Info health $(1 / 0) \times$ Dried $(1 / 0)$ & $0.675 *(0.404)$ & $0.718 *(0.429)$ \\
\hline Info environment $(1 / 0) \times \operatorname{Dried}(1 / 0)$ & $1.153^{* * *}(0.390)$ & $1.332 * * *(0.445)$ \\
\hline Number of vegetables regularly consumed ${ }^{b}$ & & $0.120 * *(0.055)$ \\
\hline Previous knowledge of the term 'pulses' $(1 / 0)^{\mathrm{c}}$ & & $3.505 * * *(0.699)$ \\
\hline Number of persons in the household & & $-0.668^{* * *}(0.232)$ \\
\hline$\sigma^{\mathrm{d}}$ & $15.555(99.960)$ & $8.110^{* * *}(0.778)$ \\
\hline Observations & $\mathrm{n}=1,200$ & $\mathrm{n}=1,200$ \\
\hline Log likelihood & -577.11 & -559.82 \\
\hline \multicolumn{3}{|c|}{ a***,**,* significant at 1,5 and $10 \%$, respectively. Standard errors in parentheses. } \\
\hline \multicolumn{3}{|c|}{${ }^{\mathrm{b}}$ Sum of dummy variable $=1$ for vegetables consumed at least 4 times in the last year, over a list of 16 vegetables. } \\
\hline \multicolumn{3}{|c|}{${ }^{\mathrm{c}}$ Dummy variable $=1$ for a checked off 'Yes' to the question 'Do you know what the term 'pulses' mean?' } \\
\hline \multicolumn{3}{|c|}{$\begin{array}{l}\text { d Standard deviation related to the random effect estimator implying the individual specific effect treated as a random variable, with } \\
\text { a mean } 0 \text { and a variance } \sigma^{2} \text {. }\end{array}$} \\
\hline
\end{tabular}

Table 6. Estimations of purchase intents in Germany with random effects logit estimator. ${ }^{\text {a }}$

\begin{tabular}{|c|c|c|}
\hline Independent variables & Yes Model 1 & Yes Model 2 \\
\hline Price & $-1.771 * * *(0.340)$ & $-3.617 * * *(0.499)$ \\
\hline Pasta $(1 / 0)$ & $-1.527(1.079)$ & $-0.952(0.587)$ \\
\hline Info health $(1 / 0) \times$ Pasta $(1 / 0)$ & $2.527 * * *(0.752)$ & $2.398^{* * *}(0.628)$ \\
\hline Info environment $(1 / 0) \times$ Pasta $(1 / 0)$ & $2.761 * * *(0.765)$ & $2.349 * * *(0.601)$ \\
\hline Info health $(1 / 0) \times$ Dried $(1 / 0)$ & $1.233 * *(0.616)$ & $1.090 * *(0.530)$ \\
\hline Info environment $(1 / 0) \times$ Dried $(1 / 0)$ & $1.807 * * *(0.522)$ & $2.084 * * *(0.584)$ \\
\hline Purchaser of food in the household $(1 / 0)^{b}$ & & $1.071 * *(0.456)$ \\
\hline Specific diet trying to reduce meat $(1 / 0)^{c}$ & & $1.218^{* * *}(0.470)$ \\
\hline Regular purchasing of organic fruits \& vegetables $(1 / 0)^{\mathrm{d}}$ & & $1.332 * * *(0.456)$ \\
\hline Previous knowledge of the term 'pulses' $(1 / 0)^{\mathrm{e}}$ & & $3.078^{* * *}(0.663)$ \\
\hline Woman $(1 / 0)$ & & $1.720 * * *(0.559)$ \\
\hline Age & & $-0.084 * * *(0.014)$ \\
\hline Number of persons in the household & & $0.400 * *(0.167)$ \\
\hline High degree for education $(1 / 0)^{\mathrm{f}}$ & & $2.087 * * *(0.543)$ \\
\hline Living in a rural area $(1 / 0)^{\mathrm{g}}$ & & $1.829 * * *(0.557)$ \\
\hline$\sigma^{\mathrm{h}}$ & $6.645 * * *(0.699)$ & $8.854 * * *(0.876)$ \\
\hline Observations & $\mathrm{n}=1,200$ & $\mathrm{n}=1,200$ \\
\hline Log likelihood & -489.24 & -459.18 \\
\hline \multicolumn{3}{|c|}{ a***,** significant at 1 and $5 \%$, respectively. Standard errors in parentheses. } \\
\hline \multicolumn{3}{|c|}{ b Dummy variable $=1$ for only or mainly 'responsible for purchasing food in the household'. } \\
\hline \multicolumn{3}{|c|}{ ' Dummy variable $=1$ for checking off 'I try to reduce meat'. } \\
\hline \multicolumn{3}{|c|}{${ }^{\mathrm{d}}$ Dummy variable $=1$ if exclusively or mainly organic consumers of fruits and vegetables. } \\
\hline \multicolumn{3}{|c|}{ e Dummy variable $=1$ for a checked off 'Yes' to the question 'Do you know what the term 'pulses' mean?' } \\
\hline \multicolumn{3}{|c|}{${ }^{\mathrm{f}}$ Dummy variable $=1$ for university/college degree. } \\
\hline \multicolumn{3}{|l|}{$\mathrm{g}$ Dummy variable $=1$ to 1 for living in a rural area. } \\
\hline
\end{tabular}


Table 7. Estimations of purchase intents in Poland with random effects logit estimator. ${ }^{\mathrm{a}}$

\begin{tabular}{|c|c|c|}
\hline Independent variables & Yes Model 1 & Yes Model 2 \\
\hline Price & $-0.280 * * *(0.046)$ & $-0.501 * * *(0.063)$ \\
\hline Pasta $(1 / 0)$ & $-0.895(0.545)$ & $-1.859 * * *(0.528)$ \\
\hline Info health $(1 / 0) \times$ Pasta $(1 / 0)$ & $1.606 * * *(0.461)$ & $1.527 * * *(0.488)$ \\
\hline Info environment $(1 / 0) \times$ Pasta $(1 / 0)$ & $2.005 * * *(0.438)$ & $2.278 * * *(0.484)$ \\
\hline Info health $(1 / 0) \times$ Dried $(1 / 0)$ & $1.174 * * *(0.382)$ & $1.356 * * *(0.411)$ \\
\hline Info environment $(1 / 0) \times$ Dried $(1 / 0)$ & $1.160 * * *(0.367)$ & $1.043 * * *(0.400)$ \\
\hline Vegetarian $(1 / 0)^{\mathrm{b}}$ & & $1.827 * *(0.860)$ \\
\hline Specific diet trying to reduce meat $(1 / 0)^{\mathrm{c}}$ & & $2.457 * * *(0.750)$ \\
\hline Regular purchasing of organic fruits \& vegetables $(1 / 0)^{\mathrm{d}}$ & & $1.840 * * *(0.452)$ \\
\hline Regular consumption of pulses $(1 / 0)^{\mathrm{e}}$ & & $2.126 * * *(0.454)$ \\
\hline$\sigma^{f}$ & $5.795 * * *(1.070)$ & $5.495 * * *(0.468)$ \\
\hline Observations & $\mathrm{n}=1,200$ & $\mathrm{n}=1,200$ \\
\hline Log likelihood & -616.60 & -576.96 \\
\hline \multicolumn{3}{|c|}{ a***,** significant at 1 and $5 \%$, respectively. Standard errors in parentheses. } \\
\hline \multicolumn{3}{|c|}{ b Dummy variable $=1$ for vegetarian. } \\
\hline \multicolumn{3}{|c|}{ ' Dummy variable $=1$ for checking off 'I try to reduce meat'. } \\
\hline \multicolumn{3}{|c|}{ d Dummy variable $=1$ if exclusively or mainly organic consumers of fruits and vegetables. } \\
\hline \multicolumn{3}{|c|}{ e Dummy variable $=1$ for consumption pulses $\geq$ twice a week. } \\
\hline \multicolumn{3}{|c|}{$\begin{array}{l}\text { f Standard deviation related to the random effect estimator implying the individual specific effect treated as a random variable, with } \\
\text { a mean } 0 \text { and a variance } \sigma^{2} \text {. }\end{array}$} \\
\hline
\end{tabular}

Table 8. Estimations of purchase intents in UK with random effects logit estimator. ${ }^{a}$

\begin{tabular}{|c|c|c|}
\hline Independent variables & Yes Model 1 & Yes Model 2 \\
\hline Price & $-2.285^{* * *}(0.284)$ & $-0.257(0.401)$ \\
\hline Pasta $(1 / 0)$ & $-0.842(0.563)$ & $-1.217 * *(0.554)$ \\
\hline Info health $(1 / 0) \times$ Pasta $(1 / 0)$ & $1.267 * *(0.621)$ & $1.491 * *(0.682)$ \\
\hline Info environment $(1 / 0) \times$ Pasta $(1 / 0)$ & $1.604 * *(0.711)$ & $1.309 * *(0.592)$ \\
\hline Info health $(1 / 0) \times$ Dried $(1 / 0)$ & $1.326 * *(0.590)$ & $1.732 * * *(0.606)$ \\
\hline Info environment $(1 / 0) \times$ Dried $(1 / 0)$ & $0.169(0.562)$ & $0.185(0.56)$ \\
\hline Regular purchasing of organic fruits \& vegetables $(1 / 0)^{b}$ & & $1.823 * * *(0.692)$ \\
\hline Age & & $-0.085^{* * *}(0.017)$ \\
\hline$\sigma^{c}$ & $6.843 * * *(0.564)$ & $7.532 * * *(0.729)$ \\
\hline Observations & $\mathrm{n}=1,200$ & $\mathrm{n}=1,200$ \\
\hline Log likelihood & -448.67 & -433.04 \\
\hline
\end{tabular}

Tables 5, 6, 7 and 8 confirm results of Table 4 and exhibit the following results, with a few exceptions depending on country specificities. Prices negatively influence the purchase intents of products, with a negative coefficient in each table. Before the revelation of information at round \#1, the choices for the pasta are lower than the ones for the dried lentils in all countries (namely, with a negative coefficient linked to the variable 'Pasta'). The revelation of information leads to significant shifts in choices in all these tables. In France and Germany, the reactions to information on purchase intent of pasta (Info health $\times$ Pasta and Info environment $\times$ Pasta) are respectively higher than the reactions in the purchase intent of dried lentils 
(Info health $\times$ Dried and Info environment $\times$ Dried). Moreover, for each product, the impact of information about health is lower than the one related to the information about environment. In Poland, the situation is slightly different. Here the impact of information on the environment is stronger than the one on health for pasta, while the impact of information on health and environment is almost the same when considering dried lentils. The impact of information in the UK is less than the one in the other countries, in particular for dried lentils and for the message on environmental effects.

Despite national differences, the main results are invariant across the four countries. Although not systematic, it is important to note that the message on the environment has often a higher impact on purchase intents than the message on health, as indicated by the estimated coefficients of Model 1 in Tables 5 to 8 . This ranking is verified for 6 cases over 8 possibilities related to the 4 countries and the two products concerned by the two messages. One explanation could be the novelty and the relative precision of the environmental message focusing on crop diversification.

For each table, Model 2 shows the additional influence of various variables related to some consumption habits. In general, high consumption of vegetables, previous knowledge of the term 'pulses', regular consumption of organic fruits and vegetables, or trying to reduce meat consumption (Germany and Poland) or being vegetarian (Poland) positively influence the purchase intents of lentils. In other words, consumers with established practices regarding vegetables and legumes are prone to accept to purchase the lentils at round \#1. Note that the signs and the coefficients of variables present in Model 1 are not modified with Model 2, in particular the ones related to the revelation of health and environmental messages. In other words, results from Model 1 are robust when integrating consumer perceptions and sociodemographic variables as done in Model 2.

We also ran other robustness checks. First, we estimated the model with many different socio-demographic variables before leading to Model 2. The signs and the coefficients of variables also present in Model 1 were not modified with these models conferring a robustness to the estimations of previous Tables 5 to 8 . Second, we ran other estimations by pooling French, German, Polish and British data. Again, results are qualitatively similar confirming the significance of variables related to the health and environment messages. We now focus on the replies to some additional questions following the revelation of messages and purchase intent questions.

Table 9 presents consumers' reactions following the messages revelation and the indication of purchase intents. Even if a vast majority found that the revealed message is important, they are less likely to think they will eat more pulses in the future. Additionally, after the revelation of messages between $25 \%$ and $42 \%$ of consumers declared they plan to eat more pulses in the future. This result is in line with findings of the third column of Table 4 (the $\%$ of Yes at round \#2), with very close figures. Consumers rather see the responsibility in the hand of the government to support farmers or restaurants to offer more lentils-based dishes than in their

Table 9. Reaction to revealed messages and consumption intent in the future.

\begin{tabular}{|c|c|c|c|c|}
\hline & France & Germany & Poland & $\mathbf{U K}$ \\
\hline Is the revealed message important? $\%$ of yes & 64 & 65.8 & 80.3 & 67.8 \\
\hline Eating more pulses in the future? $\%$ of yes & 38 & 25 & 42.1 & 24.1 \\
\hline Should the government subsidize farmers for planting more legumes? $\%$ of yes & 51.8 & 41.6 & 61.3 & 41.5 \\
\hline Should restaurants offer more dishes with lentils or pulses? \% of yes & 74 & 56.3 & 68.8 & 53.6 \\
\hline \multicolumn{5}{|l|}{ Most convincing new label signaling environmental benefits, $\%$ of checked-off ${ }^{a}$} \\
\hline Cultivating lentils favors crop diversification & 18.3 & 11 & 17 & 10.8 \\
\hline Cultivating lentils favors biodiversity & 29.5 & 13.5 & 15.3 & 15.5 \\
\hline Cultivating lentils favors the environment & 30.8 & 51.2 & 49.8 & 45.7 \\
\hline No opinion & 21.3 & 24.3 & 17.8 & 28 \\
\hline
\end{tabular}

a Single choice. 
own consumption choices. At the bottom of Table 9, we also report the respondents' opinion about possible claims for a label that could signal environmental benefits related to lentils growing. The claim 'Cultivating lentils favors the environment' seems to dominate other claims in Germany, Poland and the UK. In France it is at equal level with 'Cultivating lentils favors biodiversity', that in the other three countries does not seem to resonate with consumers. Also, the claim 'Cultivating lentils favors crop diversification' does not seem very convincing for most consumers, maybe because it is perceived as too narrow and specific.

Eventually, Table 10 shows how consumers evaluate the different options for improving the sustainability of the food system, a question going beyond the boost for legumes. Sustaining farmers in the effort to plant legumes collected important 'ballots'. Avoiding food waste by both supply chains and consumers also matter for many consumers. From 42 to $60 \%$ of consumers recognize that changing consumption behavior would contribute to the sustainability of the system, which seems to indicate a significant awareness. However, the solution consisting in taxing unhealthy food is not backed by many consumers, the same holds for eating less meat that is not a favored option, except in Germany.

\section{Discussion}

\subsection{Limited changes in consumption}

We found that the messages resulted in small but significant changes in participant intention to purchase lentils in France, Germany, Poland, and the UK (RQ a, Table 4). Tables 5, 6, 7 and 8 show that these relatively weak effects of messages are similar across countries and products (RQ b). Interestingly, the message about environmental benefits and crops diversification had often a greater impact on purchase intent than did information about the food's nutritional benefits (RQ c). This sensitivity to environmental characteristics seems in line with recent observations showing a significant increase of environmental claims for legumes food packets in Europe over the last decade (Lascialfari et al., 2019).

With the present paper, it is important to note that estimates of purchase intent represent an upper bound for possible purchasing patterns in real contexts. Indeed, purchasing intentions are likely to fade when consumers enter supermarkets because of several factors, including imperfect recall, information overload, and grocery list length, which can all complicate the task of retaining precise information about a given product.

The results show that $24-42 \%$ of all the study participants expressed a readiness to eat more pulses (Table 9). These figures (Tables 3 and 8) greatly contrast with those published by the EAT-Lancet Commission, calling for a shift toward more healthy and sustainable diets. Recall that, to arrive at the healthy diet recommended by Willet et al. (2019), legume consumption in Europe would need to quintuple, which would represent a

Table 10. The best idea for improving sustainability of the food system. ${ }^{\mathrm{a}}$

\begin{tabular}{|c|c|c|c|c|}
\hline Idea effective to improve the sustainability of the food system & France & Germany & Poland & UK \\
\hline Government supporting sustainable farming practices, \% checked-off & 46.2 & 54.8 & 54.2 & 62.8 \\
\hline Government taxing unhealthy foods high in fat and sugar, $\%$ checked-off & 32.3 & 34 & 26.3 & 35.8 \\
\hline $\begin{array}{l}\text { Farmers and food industry investing in better production processes, } \\
\% \text { checked-off }\end{array}$ & 30 & 33.5 & 41.8 & 46.2 \\
\hline Farmers and food industry avoiding food waste, $\%$ checked-off & 57.8 & 53.3 & 50.2 & 64.5 \\
\hline Consumers changing consumption habits, $\%$ checked-off & 42.7 & 60.7 & 42.8 & 50.2 \\
\hline Consumers eating less meat, $\%$ checked-off & 29.5 & 50.5 & 26 & 38.8 \\
\hline Consumers avoiding food waste, $\%$ checked-off & 66.3 & 65.8 & 58.3 & 73.8 \\
\hline None of the previous ideas, $\%$ checked-off & 6 & 6.8 & 4.3 & 5.5 \\
\hline
\end{tabular}

${ }^{a}$ Multiple answers possible. 
much greater shift than our results suggest could be accomplished. Other research has also indicated that more dramatic dietary changes would be needed (Aiking and De Boer, 2020; Auestad and Fulgoni, 2015; De Boer and Aiking, 2021; Lock et al., 2010; Tilman and Clark, 2014). In order to successfully bring about the dietary shifts described by this literature, there would also need to be considerable upheaval in both crop farming practices and culinary habits (Marette and Réquillart, 2020).

\subsection{Alternative cooking practices}

Our study indicates that many consumers in Europe are not prepared to make drastic changes in their purchases of legumes/pulses, a food type universally recognized for the sustainability of its production system. This finding fits with what has been seen in previous studies - that actual dietary changes remain limited (Aiking and de Boer, 2020; De Boer et al., 2007; Hartmann and Siegrist, 2017; Siegrist et al., 2015). However, even if our study did not observe a strong response, our results do suggest that consumers may be sensitive to food's environmental benefits, including the issue of crop diversification. Indeed, a vast majority of the study participants expressed that the latter information was important (Table 9). This finding should encourage us to think beyond 'modern' food science when we are considering transformations in the way we eat. For example, it could be useful to focus on reinventing ancestral practices that involve growing and cooking legumes (McClements, 2019). It might also be necessary to favor the development of new legume-based foods, as the lentil pasta shown to some participants in our study. The purchasing intents for the lentil pasta are slightly lower than the ones for classical dried lentils (Table 4), suggesting a weak impact coming from these new products. Despite this limited influence, it is important to continue the development of new products that also include legume burger patties that are viable substitutes for meat patties (Castellari, et al., 2019).

Figueiara et al. (2019) underscored that consumer understanding of legumes and related culinary practices plays an important role. The analysis of the responses to the web survey's culinary questions revealed that three important factors, namely the participant's health awareness, cooking skills, and cognitive flexibility, may have influenced the impact of the informational messages. While significant differences existed in the relevance of these factors among countries, there was no clear overarching influence on purchase intent. While these three factors may promote the consumption of plant-based meals (Graça et al., 2019), we found that they are unlikely to drive purchasing behaviors.

Consumption behaviors may be also influenced by many parameters related to cooking practices and purchasing contexts. These parameters particularly include cooking lessons on TV or at school for beefing up knowledge. They integrate the possibilities to offer more legume dishes in collective catering, in particular at school (Magrini et al., 2021). The significant criteria also encompass shelve organization and promotion in supermarkets for awaking consumers' interest. Developing incentives to precisely sway these parameters is particularly challenging for a policy. This difficulty to change consumers' behaviors also raises questions about the best options to influence consumers' perceptions via advertising, promotions, taxes, subsidies, etc. Some of these options are now briefly presented.

\subsection{The regulatory options}

It is evident that bringing about marked changes in legume consumption would require more than providing generic advertising, classical recommendations and informational labels stressing the food's environmental benefits (Table 9). Generic advertising using the scientific messages that we revealed in this paper could modify the consumers' perceptions, since Melendrez-Ruiz et al. (2020) underscore that French consumers have only vague impressions regarding legumes and their social representation. If we look at the variation in purchase intent (Table 4), it would appear that providing information does little to shift consumer behavior. The life span of revealed information via public recommendations is likely to quickly fade after a short period of time, since consumers constantly receive new messages. The proliferation of information drastically reduces the efficiency of any new recommendation. That said, $64-80 \%$ of participants indicated that the information provided was important (Table 9), which could justify the implementation of regulatory 
interventions. Magrini et al. (2018) underline the necessity of defining a strong public regulation to provide incentives along the supply chain for boosting crop diversification. Our results show that consumers choices are not a sufficient driver for promoting crop diversification and developing legumes cultivation, which requires to select other instruments such as norms, subsidies and/or taxes.

If the EAT-Lancet Commission (Willet et al., 2019) and other collaborators wish to achieve their ambitious objectives, other instruments will need to be deployed by European regulators. For example, helping farmers plant legumes and encouraging their use of longer crop rotations is one option that participants seemed to support (Table 9), even if: (1) crop rotation length depends on many factors and makes for a difficult policy target; and (2) farmers would need to receive substantial subsidies before undertaking a major shift toward legume cultivation. Depending on both nitrogen balance/cycle and soil quality, these subsidies to farmers could be part of an ambitious environmental policy related the European Green Deal (Matthews, 2020). Another option could be directly subsidizing consumer purchases of lentils (as well as other types of pulses). Finally, taxing highly processed foods, energy-dense foods, and/or meat while also subsidizing purchases of legumes, fruits, and vegetables could help move dietary habits in the direction of plant-based proteins. However, taxing unhealthy and unsustainably produced foods sold in supermarkets was not an option backed by many participants (Table 10), which constrains certain possible actions that could be taken to promote dietary changes.

\section{Conclusions}

Despite certain shortcomings in the web survey results, we were able to answer some important research questions related to lentil and legume consumption. Although the results differed slightly among countries, our general findings were rather consistent. We discovered that informational messages could significantly influence purchase intent (RQ b), even if only weakly ( $<10 \%$ of participants expressed a change of mind). The impact was dependent on product type (i.e. dried lentils vs lentil pasta, RQ b) and information type (i.e. nutritional vs environmental benefits RQ c). More specifically, after reading a message describing the benefits of lentils, $25-42 \%$ of participants stated that they planned to eat more pulses in the future.

We implemented in this study a simple referendum mechanism of choices with the options 'Yes', 'No' and 'Maybe', which is particularly tailored for measuring the impact of revealed information with heterogeneous consumers. Our analysis could accommodate alternative mechanisms for eliciting choices. This referendum type allows to get purchase intents for a generic product and for possible and credible market prices. A choice experiment could be used for estimating choices for differentiated products with various characteristics signaled by labels. The choices in a supermarket, namely in a field experiment, could be studied for seeing how consumers react to advertising, messages on apps or promotion for boosting lentils sales. Eventually, the debate on the origin of proteins is never over. This study extends the extant literature by focusing on protein-rich products, but not the ones specifically sold as meat alternatives or fish alternatives. Future studies could enrich the literature by considering plant-based fish alternatives. While plant-based fish alternative may provide large benefits to the environment and the future of depleted resources, the embedding of valuable nutrients, like iodine or omega-3 fatty acids, contained in fish into an alternative food matrix may remain challenging.

Our work has found that consumers in Europe are likely to reply 'just a little' when asked, at home, in supermarkets or restaurants, whether they would like more lentils or legumes. Our study suggests that we still have a long road ahead of us if we wish to substantially increase the sustainability of dietary habits, including legumes. 


\section{Supplementary material}

Supplementary material can be found online at https://doi.org/10.22434/IFAMR2021.0071

\section{Appendix A.}

Appendix B.

Table S1. Possible values of price $P=\left\{P_{1}, P_{2}, P_{3}\right\}$ for lentils (500 g) and pasta (500 g).

\section{Acknowledgements}

Without implicating them, we thank Philippe Baret, Johan Le Douce, Antoine Messean, Hania Mezghrani, and Jarosław Stalenga for their help.

This research has received funding from the European Union's Horizon 2020 research and innovation program under the grant agreement No 727482, DiverIMPACTS, and from the French Agence Nationale de la Recherche (ANR) under the grant agreement DIETPLUS ANR-17-CE21-0003. The funders had no role in study design, data collection and analysis, decision to publish, or preparation of the manuscript. The authors only are responsible for any omissions or deficiencies.

\section{Conflict of interest}

The authors declare that they have no known competing financial interests or personal relationships that could have appeared to influence the work reported in this paper.

\section{References}

Aiking, H. and J. De Boer. 2020. The next protein transition. Trends in Food Science and Technology 105: 515-522.

Alcon, F., C. Marin-Minano, J.A. Zabala, M.D. De-Miguel and J.M. Martinez-Paz. 2020. Valuing diversification benefits through intercropping in Mediterranean agroecosystems: a choice experiment approach. Ecological Economics 171: 106593.

Auestad, N. and V.L. Fulgoni. 2015. What current literature tells us about sustainable diets: emerging research linking dietary patterns, environmental sustainability, and economics. Advances in Nutrition 6(1): 19-36.

Castellari, E., S. Marette, D. Moro and P. Sckokai. 2019. The impact of information on willingness to pay and quantity choices for meat and meat substitute. Journal of Agricultural and Food Industrial Organization 17(1): 20170028.

Cerri, J., J. Thøgersen and F. Testa. 2019. Social desirability and sustainable food research: a systematic literature review. Food Quality and Preference 71: 136-140.

Croissant, Y. 2017. Package pglm: panel generalized linear models. R package version 0.2-1. Available at: https://cran.r-project.org/web/packages/pglm/pglm.pdf

De Boer, J. and H. Aiking. 2021. Favoring plant instead of animal protein sources: legitimation by authority, morality, rationality and story logic. Food Quality and Preference 88: 104098.

De Boer, J., C.T. Hoogland and J.J. Boersema. 2007. Towards more sustainable food choices: value priorities and motivational orientations. Food Quality and Preference 18(7): 985-996.

DiverImpacts. 2020. European project H2020. Available at: https://www.diverimpacts.net/

Figueira, N., F. Curtain, E. Beck and S. Grafenauer. 2019. Consumer understanding and culinary use of legumes in Australia. Nutrients 11(7): 1575.

González, A.D., B. Frostell and A. Carlsson-Kanyama. 2011. Protein efficiency per unit energy and per unit greenhouse gas emissions: Potential contribution of diet choices to climate change mitigation. Food Policy 36: 562-570. 
Graça, J., M. Truninger, L. Junqueira and L. Schmidt. 2019. Consumption orientations may support (or hinder) transitions to more plant-based diets. Appetite 140: 19-26.

Hartmann, C. and M. Siegrist. 2017. Consumer perception and behaviour regarding sustainable protein consumption: a systematic review. Trends in Food Science and Technology 61: 11-25.

Intergovernmental Panel on Climate Change (IPCC). 2019. Climate change and land: an IPCC special report on climate change, desertification, land degradation, sustainable land management, food security, and greenhouse gas fluxes in terrestrial ecosystems. IPCC, Geneva, Switzerland. Available at: https://www.ipcc.ch/srccl/

Irz, X., P. Leroy, V. Réquillart and L.G. Soler. 2015. Economic assessment of nutritional recommendations. Journal of Health Economics 39: 188-210.

Keller, K.L. and R. Staelin. 1989. Assessing biases in measuring decision effectiveness and information overload. Journal of Consumer Research 15: 504-508.

Knight, J.D. 2012. Frequency of field pea in rotations impacts biological nitrogen fixation. Canadian Journal of Plant Science 92: 1005-1011.

Lascialfari, M., M. Magrini and P. Triboulet. 2019. The drivers of product innovations in pulse-based foods: insights from case studies in France, Italy and USA. Journal of Innovation Economics and Management 1(1): 111-143.

Lee, S.C. 2019. A computational note on maximum likelihood estimation in random effects panel probit model. Communications for Statistical Applications and Methods 26: 315-323.

Lemken, D., A. Spiller and B. Schulze-Ehlers. 2019. More room for legume - consumer acceptance of meat substitution with classic, processed and meat-resembling legume products. Appetite 143: 104412.

Lin, B. 2011. Resilience in agriculture through crop diversification: adaptive management for environmental change. BioScience 61(3): 183-193.

Lock, K., R.D. Smith, A.D. Dangour, M. Keogh-Brown, G. Pigatto, C. Hawkes, R.M. Fisberg, and Z. Chalabi. 2010. Health, agricultural, and economic effects of adoption of healthy diet recommendations. The Lancet 376(9753): 1699-1709.

Loomis J. and E. Ekstrand. 1998. Alternative approaches for incorporating respondent uncertainty when estimating willingness to pay: the case of the Mexican spotted owl. Ecological Economics 27: 29-41.

Lusk, J.L. 2003. Effects of cheap talk on consumer willingness-to-pay for golden rice. American Journal of Agricultural Economics 85(4): 840-856.

Magrini, M.-B., H. Fernandez-Inigo, A. Doré and O. Pauly. 2021. How institutional food services can contribute to sustainable agrifood systems? Investigating legume serving, cooking and sourcing through France in 2019. Review of Agricultural, Food and Environmental Studies. https://doi. org/10.1007/s41130-021-00146-y

Magrini, M.-B., M. Anton, C. Cholez, G. Corre-Hellou, G. Duc, M.H. Jeuffroy, J.M. Meynard, E. Pelzer, A.S. Voisin and S. Walrand. 2016. Why are grain-legumes rarely present in cropping systems despite their environmental and nutritional benefits? Analyzing lock-in in the French agrifood system. Ecological Economics 126: 152-162.

Magrini, M.-B., M. Anton, J.M. Chardigny, G. Duc, M. Duru, M.H. Jeuffroy, J.M. Meynard, V. Micard and S. Walrand. 2018. Pulses for sustainability: breaking agriculture and food sectors out of lock-in. Frontiers in Sustainable Food Systems 2: 64-76.

Marette, S. and V. Réquillart. 2020. Dietary models and challenges for economics. Review of Agricultural, Food and Environmental Studies 101(1): 5-22.

Martin, C., C. Lange and S. Marette. 2021. Importance of additional information, as a complement to information coming from packaging, to promote meat substitutes: case study on a sausage based on vegetable proteins. Food Quality and Preference 87: 104058.

Matthews, A. 2020. Agriculture in the European Green Deal: from ambition to action. Cap Reform. Available at: http://capreform.eu/agriculture-in-the-european-green-deal-from-ambition-to-action/

McClements, D.J. 2019. Future foods: how modern science is transforming the way we eat. Springer Scientific, New York, NY, USA.

Meier, C. and B. Oehen. 2019. Consumers' valuation of farmers' varieties for food system diversity. Sustainability 11(24): 7134. 
Melendrez-Ruiz, J., G. Arvisenet, V. Laugel, S. Chambaron and S. Monnery-Patris. 2020. Do French consumers have the same social representations of pulses as food industry professionals? Foods 9(2): 147.

Mintel. 2021. Global new product database. Mintel, London, UK. Available at: https://www.mintel.com/ global-new-products-database

Mitchell, D.C., F.R. Lawrence, T.J. Hartman and J.M. Curran. 2009. Consumption of dry beans, peas, and lentils could improve diet quality in the US population. Journal of American Diet Association 109(5): 909-913.

Morel, K., E. Revoyron, M. San Cristobal and P. Baret. 2020. Innovating within or outside dominant food systems? Different challenges for contrasting crop diversification strategies in Europe. PLoS ONE 15(3): e0229910.

Poore, J. and T. Nemecek. 2018. Reducing food's environmental impacts through producers and consumers. Science 360: 987-992.

Saint-Eve, A., F. Irlinger, C. Pénicaud, I. Souchon and S. Marette. 2021. Consumer preferences for new fermented food products that mix animal and plant protein sources. Food Quality and Preference 99: 104117.

Schösler, H., J. De Boer and J.J. Boersema. 2012. Can we cut out the meat of the dish? Constructing consumeroriented pathways towards meat substitution. Appetite 58(1): 39-47.

Siegrist, M., V.H.M. Visschers and C. Hartmann. 2015. Factors influencing changes in sustainability perception of various food behaviors: results of a longitudinal study. Food Quality and Preference 46: 33-39.

Slade, P. 2018. If you build it, will they eat it? Consumer preferences for plant-based and cultured meat burgers. Appetite 125: 428-437.

Tilman, D. and M. Clark. 2014. Global diets link environmental sustainability and human health. Nature 515: 518-522.

Tobler, C., V.H.M. Visschers and M. Siegrist. 2011. Eating green. Consumers' willingness to adopt ecological food consumption behaviors. Appetite 57(3): 674-682.

Vainio A., X. Irz and H. Hartikainen. 2018. How effective are messages and their characteristics in changing behavioural intentions to substitute plant-based foods for red meat? The mediating role of prior beliefs. Appetite 125: 217-224.

Weinrich, R. 2019. Opportunities for the adoption of health-based sustainable dietary patterns: a review on consumer research of meat substitutes. Sustainability 11(15): 4028.

Weinrich, R. and O. Elshiewy, O. 2019. Preference and willingness to pay for meat substitutes based on micro-algae. Appetite 142: 104353.

Westhoek H., J.P. Lesschen, T. Rood, S. Wagner, A. De Marco, D. Murphy-Bokern, A. Leip, H. Van Grinsven, M.A. Sutton and O. Oenema. 2014. Food choices, health and environment: effects of cutting Europe's meat and dairy intake. Global Environmental Change 26: 196-205.

Willett, W., J. Rockström, B. Loken, M. Springmann, T. Lang, S. Vermeulen, T. Garnett, D. Tilman, F. DeClerck, A. Wood, M. Jonell, M. Clark, L.J. Gordon, J. Fanzo, C. Hawkes, R. Zurayk, J.A. Rivera, W.D. Vries, L.M. Sibanda, A. Afshin, A. Chaudhary, M. Herrero, R. Agustina, F. Branca, A. Lartey, S. Fan, B. Crona, E. Fox, V. Bignet, M. Troell, T. Lindahl, S. Singh, S.E. Cornell, K.S. Reddy, S. Narain, S. Nishtar and C. J.L Murray. 2019. Food in the anthropocene: the Eat-Lancet Commission on healthy diets from sustainable food systems. The Lancet 393(10170): 447-492. https://doi. org/10.1016/s0140-6736(18)31788-4 
